\title{
APLIKASI KESEHATAN MENENTUKAN JENIS PENYAKIT LAMBUNG DENGAN MENGAMBIL BEBERAPA GEJALA MENGGUNAKAN METODE FUZZY - MAMDANI
}

\author{
Devri Suherdi *, Putra Ramadan Nasution** \\ * Sistem Informasi, STMIK Triguna Dharma \\ ** Sistem Informasi, Universitas Islam Sumatera Utara
}

\begin{abstract}
Abstrak
Penelitian ini dilakukan untuk mendiagnosa penyakit lambung yang lebih spesifik pada manusia yaitu grastitis, maag, kanker lambung, tumor lambung / polip lambung, dispesia, gerd, gastroparesis dan gastroenteritis, dengan adanya gejala yang lebih spesifik maka persentase kemungkinan terjangkitnya penyakit lambung akan lebih besar. Sistem pakar untuk mendiagnosa penyakit lambung dengan menggunakan metode Fuzzy Mamdani dapat membantu meminimalisir peran dokter penyakit dalam sehingga pasien dapat lebih dini mendeteksi jenis penyakit lambung apa yang dideritanya. Sistem pakar berbasis web memungkinkan adanya peranan bidang informatika dalam bidang kesehatan dan dapat disimpan dalam file database yang besar sehingga lebih efisien, tepat sasaran dan mengikuti perkembangan dunia kedokteran. Dengan adanya gejala-gejala penyakit pecernaan yang dideteksi maka akan dapat didiagnosa jenis penyakit lambung apa yang di derita oleh pasien dengan hasil penelitian dapat mendeteksi jenis penyakit lambung, gejala-gejala dan solusi pengobatannya.
\end{abstract}

Kata kunci : Sistem pakar, Fuzzy Mamdani, Website, Database

\begin{abstract}
This research was conducted to diagnose gastric diseases that are more specific to humans, namely grastitis, ulcers, gastric cancer, gastric tumors / gastric polyps, dyspesia, gerd, gastroparesis and gastroenteritis. With more specific symptoms, the percentage of gastric disease will be greater. An expert system for diagnosing gastric disease using the Fuzzy Mamdani method can help minimize the role of internal medicine doctors so that patients can detect what type of gastric disease they have early. The web-based expert system allows the role of informatics in the health sector and can be stored in a large database file so that it is more efficient, on target and follows developments in the medical world. With the detected gastrointestinal symptoms, the patient will be able to diagnose what type of gastric disease suffered by the patient with the results of the research being able to detect the type of gastric disease, its symptoms and treatment solutions.
\end{abstract}

Keywords: Expert system, Fuzzy Mamdani, Website, Database

\section{PENDAHULUAN}

Sering kali kita mempunyai pertanyaan seputar gejala-gejala yang dirasakan pada tubuh kita, bisa jadi suatu gejala yang kita alami merupakan tanda dari suatu penyakit. Seperti yang akan dibahas di jurnal ini yaitu penyakit lambung, dimana penyakit lambung ini bias menjalar sampai ke bagian paling vital tubuh.

Dengan adanya aplikasi sistem pakar diagnosa penyakit lambung maka diharapkan dapat membantu para penderita lambung untuk mendiagnosa gejala awal dari penyakit lambung sebelum berkonsultasi dengan dokter spesialis lambung. Para pengguna sistem dapat menggunakan aplikasi dengan mendaftarkan dirinya ke web ini. Langkah dalam diagnosa penyakit yaitu sistem akan memberikan pertanyaan ke user dan user harus memberikan jawaban berupa gejala-gejala yang dialami. Selanjutnya 
sistem akan memberikan solusi yang tepat mengenai penyakit dan solusi yang harus dilakukan oleh penderita.

\section{METODE PENELITIAN}

Dalam kondisi yang nyata, beberapa aspek dalam dunia nyata selalu atau biasanya berada diluar model matematis dan bersifat inexact. Konsep ketidakpastian inilah yang menjadi konsep dasar munculnya konsep logika fuzzy. Pencetus gagasan logika fuzzy adalah Prof. L.A. Zadeh (1965) dari California University. Pada prinsipnya himpunan fuzzy adalah perluasan himpunan crips, yaitu himpunan yang membagi sekelompok individu kedalam dua kategori, yaitu anggota dan bukan anggota.

Pada himpunan tegas (crisp), nilai keanggotaan suatu item $\mathrm{x}$ dalam suatu himpunan A, yang sering ditulis dengan $\mu \mathrm{A}[\mathrm{x}]$, memiliki 2 kemungkinan, yaitu (Kusumadewi, 2003):

- Satu (1) yang berarti bahwa suatu item menjadi anggota dalam suatu himpunan.

- Nol (0) yang berarti bahwa suatu item tidak menjadi anggota dalam suatu himpunan. Pada himpunan crisp, nilai keanggotaan hanya 2 kemungkinan, yaitu 0 atau 1 . Sedangkan pada himpunan fuzzy nilai keanggotaan terletak pada rentang 0 sampai 1 . Semesta pembicaraan adalah keseluruhan nilai yang diperbolehkan untuk dioperasikan dalam suatu variabel fuzzy. Semesta pembicaraan merupakan himpunan bilangan real yang senantiasa naik (bertambah) secara monoton dari kiri ke kanan. Nilai semesta pembicaraan dapat berupa bilangan positif maupun negatif (Kusumadewi, 2003) .

Domain himpunan fuzzy adalah keseluruhan nilai yang diijinkan dalam semesta pembicaraan dan boleh dioperasikan dalam suatu himpunan fuzzy (Kusumadewi, 2001). Fungsi keanggotaan (membership function) adalah suatu kurva yang menunjukkan pemetaan titik-titik input data kedalam nilai keanggotaan yang memiliki interval antara 0 sampai 1 . Salah satu cara yang dapat digunakan untuk mendapatkan nilai keanggotaan adalah dengan melalui pendekatan fungsi. Ada beberapa fungsi yang bisa digunakan diantaranya,

1. representasi linear

2. representasi segitiga

3. representasi trapesium

4. representasi kurva bentuk bahu

5. representasi kurva $\mathrm{S}$

6. representasi bentuk lonceng

\section{Konteks Diagram (Diagram Context)}

Diagram konteks digunakan untuk menggambarkan keseluruhan dari sistem yang dirancang. Adapun perancangannya dapat dilihat pada gambar 1 berikut :

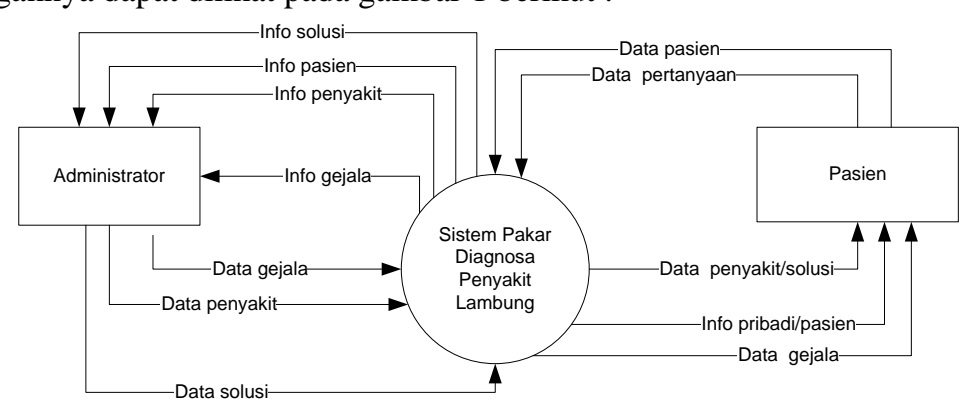

Gbr 1. Diagram Konteks (Context Diagram)

Keterangan Event list :

1. Administrator melakukan input data gejala digunakan untuk menginputkan basis pengetahuan mengenai gejala-gejala klinis yang terdapat pada lambung.

2. Administrator menginputkan penyakit yang didapatkan berdasarkan basis pengetahuan para pakar lambung. 
3. Administrator menginputkan data solusi, data solusi digunakan untuk memberikan informasi kepada pasien tentang solusi apa yang harus dilakukan apabila penyakit terdeteksi.

4. Pasien menginputkan data pribadi dalam melakukan diagnose dan data pasien akan disimpan kedalam tabel pasien.

5. Pasien mendapatkan pertanyaan dari sistem yang akan dijawab berupa gejala-gejala yang timbul pada pasien. Jawaban pertanyaan akan diproses oleh sistem pakar.

Pasien akan mendapatkan hasil mengenai diagnosa penyakit yang diderita berdasarkan gejala-gejala yang telah dijawab sebelumnya.

\section{ANALISA DAN HASIL}

Page utama atau halaman selamat datang merupakan halaman yang pertama tampil ketika pengguna mengakses halaman sistem pakar Lambung. Pada bagian utama halaman ini terdapat menu utama seperti home, diagnosa, info penyakit, about, help dan admin. Bagi pasien yang akan mendiagnosa penyakit dapat langsung menklik tombol mulai diagnosa yang akan diarahkan langsung kebagian registrasi pasien. Adapun tampilannya dapat dilihat pada gambar 2 berikut :

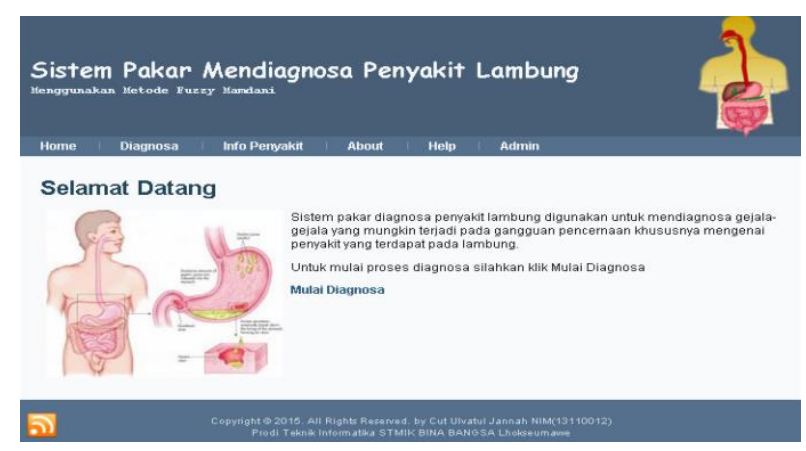

Gbr 2. Page Utama Sistem Pakar Penyakit Lambung

Page data penyakit digunakan untuk menginputkan data penyakit dan untuk menampilkan penyakit. Untuk menginputkan data penyakit maka admin harus menginputkan kode penyakit, nama penyakit, dan solusi penanganannya dan klik tombol simpan untuk menyimpannya kedalam database, untuk mengedit dapat menekan tombol edit dan hapus untuk menghapus data. Tampilannya seperti pada gambar 3 berikut

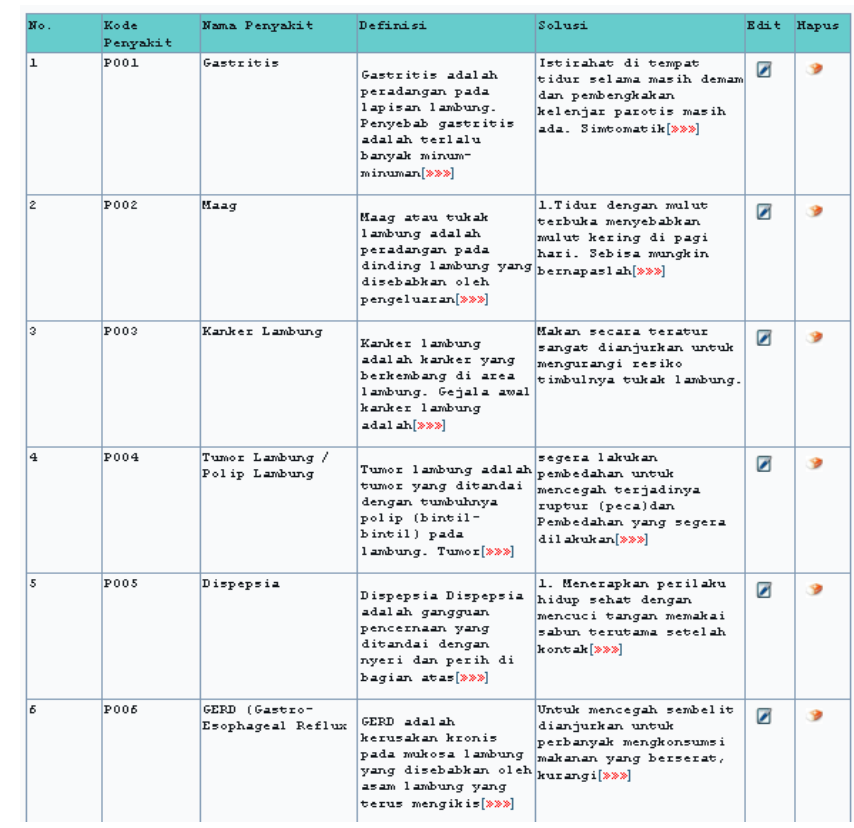

Gbr 3. Page Data Penyakit 


\subsubsection{Aplikasi Pengembangan Sistem}

1. Bahasa Pemograman

Visual Basic adalah program untuk membuat aplikasi ber-basis MicrosoftWindows secara cepat dan mudah. Form menu merupakan form yang tampil diawal pada saat program dijalankan dan berisi menu menu fitur program serta informasi dari menu tersebut.

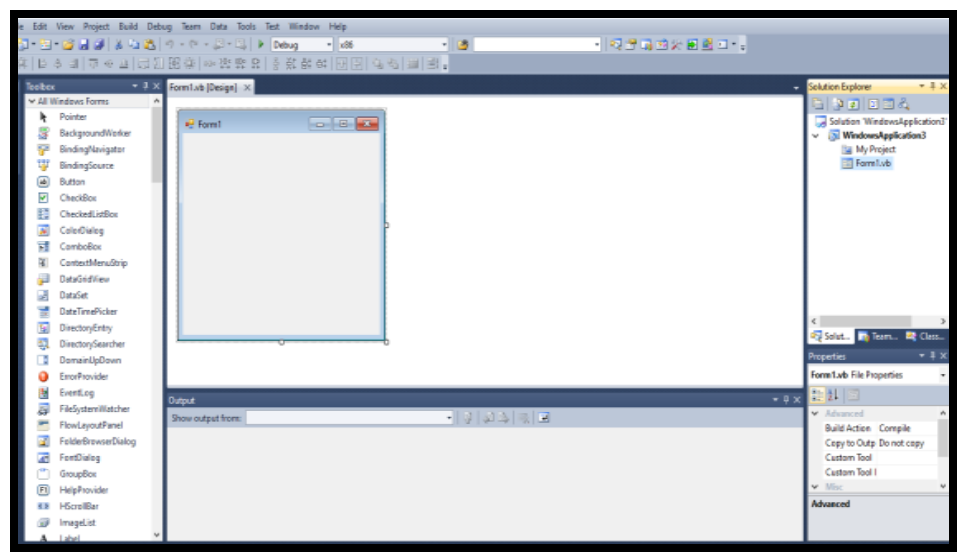

Gambar 2.1 Tampilan Visual Basic

\subsection{Desain Tabel}

Perancangan aplikasi web ini menggunakan basis data My-SQL dimana penulis membuat sebuah database dengan nama db_lambung. Database ini terdiri dari enam tabel sebagai berikut :

\section{1) Tabel Login}

Tabel login digunakan untuk menyimpan nama admin para pakar. Adapun rancangannya seperti pada tabel 1 berikut :

Tabel 1 Tabel Login

\begin{tabular}{|l|l|l|l|l|}
\hline No & $\begin{array}{l}\text { Nama } \\
\text { Field }\end{array}$ & $\begin{array}{l}\text { Type } \\
\text { Field }\end{array}$ & $\begin{array}{l}\text { Panjan } \\
\text { g }\end{array}$ & Keterangan \\
\hline 1 & $\begin{array}{l}\text { userna } \\
\text { me }\end{array}$ & $\begin{array}{l}\text { Varch } \\
\text { ar }\end{array}$ & 30 & $\begin{array}{l}\text { Nama untuk login/ } \\
\text { primary key }\end{array}$ \\
\hline 2 & $\begin{array}{l}\text { passw } \\
\text { ord }\end{array}$ & Varch & 30 & Password pengguna \\
\hline
\end{tabular}

2) Tabel Gejala

Tabel gejala (tbgejala) digunakan untuk menyimpan data gejala-gejala penyakit lambung. Adapun rancangannya seperti pada tabel 2 berikut :

Tabel 2 Tabel Gejala

\begin{tabular}{|l|l|l|l|l|}
\hline No & Nama Field & Type Field & Panjang & Keterangan \\
\hline 1 & kd_gejala & Varchar & 4 & Kode Gejala / primary key \\
\hline 2 & gejala & Varchar & 100 & Nama gejala \\
\hline
\end{tabular}

3) Tabel Penyakit

Tabel penyakit (tbpenyakit_solusi) digunakan untuk menyimpan data-data penyakit yang terdapat pada lambung. Adapun rancangannya dapat dilihat pada tabel 3 berikut : 
Tabel 3 Tabel Penyakit dan Solusi

\begin{tabular}{|l|l|l|l|l|}
\hline No & Nama Field & $\begin{array}{l}\text { Type } \\
\text { Field }\end{array}$ & $\begin{array}{l}\text { Panjan } \\
\text { g }\end{array}$ & $\begin{array}{l}\text { Keteranga } \\
\text { n }\end{array}$ \\
\hline 1 & kd_penyakit & $\begin{array}{l}\text { Varcha } \\
\text { r }\end{array}$ & 4 & $\begin{array}{l}\text { Kode } \\
\text { penyakit / } \\
\text { primary } \\
\text { key }\end{array}$ \\
\hline 2 & $\begin{array}{l}\text { nama_penya } \\
\text { kit }\end{array}$ & $\begin{array}{l}\text { Varcha } \\
\text { r }\end{array}$ & 30 & $\begin{array}{l}\text { Nama } \\
\text { penyakit }\end{array}$ \\
\hline 3 & definisi & Text & - & $\begin{array}{l}\text { Definisi } \\
\text { penyakit }\end{array}$ \\
\hline 4 & solusi & Text & - & $\begin{array}{l}\text { Solusi } \\
\text { penyakit }\end{array}$ \\
\hline
\end{tabular}

4) Tabel Relasi

Tabel relasi digunakan untuk menginputkand data relasi antara gejala dan penyakit. Pengesetan relasi ini digunakan untuk membuat rule dari berdasarkan pada metode fuzzy. Adapun rancangannya seperti pada tabel 4 berikut :

Tabel 4Tabel Relasi Gejala dan Penyakit

\begin{tabular}{|l|l|l|l|l|}
\hline No & Nama Field & Type Field & Panjang & Keterangan \\
\hline 1 & id_relasi & int & 4 & Kode relasi / primary key \\
\hline 2 & kd_gejala & Varchar & 4 & Kode gejala/foreign key \\
\hline 3 & kd_penyakit & Varchar & 4 & Kode penyakit/foreign key \\
\hline 4 & bobot & Int & 1 & Bobot penyakit \\
\hline
\end{tabular}

5) Tabel Analisa Hasil

Tabel analisa hasil digunakan untuk menampung data hasil dari diagnosa penyakit yang dilakukan oleh pasien. Adapun rancangan tabelnya dapat dilihat pada tabel 5 berikut :

Tabel 5 Tabel Analisa Hasil

\begin{tabular}{|l|l|l|l|l|}
\hline No & Nama Field & Type Field & Panjang & Keterangan \\
\hline 1 & id & Int & 4 & Id pasien / primary key \\
\hline 4 & nama & Varchar & 30 & Nama pasien \\
\hline 5 & kelamin & Varchar & 10 & Jenis kelamin \\
\hline 6 & umur & Int & 3 & Umur pasien \\
\hline 7 & alamat & Varchar & 100 & Alamat pasien \\
\hline 8 & kd_penyakit & Varchar & 4 & Kode penyakit / foreign key \\
\hline 9 & tanggal & Date & - & Tanggal diagnosa \\
\hline 10 & email & Varchar & 20 & Email pengguna \\
\hline
\end{tabular}


6) Tabel Tmp Pasien

Tabel tmp pasien digunakan untuk menampung sementara data pasien yang melakukan registrasi dan diagnosa pada web sistem pakar penyakit lambung. Adapun rancangan tabelnya dapat dilihat pada tabel 6 berikut :

Tabel 6 Tabel Tmp Pasien

\begin{tabular}{|l|l|l|l|l|}
\hline No & $\begin{array}{l}\text { Nama } \\
\text { Field }\end{array}$ & Type Field & $\begin{array}{l}\text { Panja } \\
\text { ng }\end{array}$ & Keterangan \\
\hline 1 & id & Int & 4 & $\begin{array}{l}\text { Id pengguna / } \\
\text { primary key }\end{array}$ \\
\hline 2 & nama & Varchar & 30 & Nama pasien \\
\hline 3 & kelamin & Varchar & 10 & Jenis kelamin \\
\hline 4 & umur & Varchar & 3 & Umur pasien \\
\hline 5 & alamat & Varchar & 100 & $\begin{array}{l}\text { Alamat } \\
\text { pasien }\end{array}$ \\
\hline 6 & tanggal & Date & - & $\begin{array}{l}\text { Tanggal } \\
\text { diagnosa }\end{array}$ \\
\hline 7 & email & Varchar & 20 & Email pasien \\
\hline
\end{tabular}

\section{KESIMPULAN}

Adapun harapan dari penulis untuk penggunaan website sistem pakar diagnosa penyakit Lambung dapat diperhatikan untuk para peneliti selanjutnya agar dapat melakukan uji coba pada penyakit lambung yang lebih spesifik lagi dan ditambahkan beberapa jenis penyakit pencernaan.

\section{REFERENSI}

[1] Sukma, D. (2016). Seperti Ini Penerapan Internet Of Things Di Indonesia. Diakses tanggal 20 Februari 2017 dari https://arenalte.com/berita/industri/ini-penerapan-internet-of-things-indonesia/a

[2] Kusumadewi, Sri, 2000, "Perancangan Sistem fuzzy : Studi Kasus Prediksi Jumlah Produksi dan Harga Jual Barang" dalam Jurnal Teknologi Industri Volume 5, No.1. Jogjakarta: Jurusan Teknik Industri Fakultas Teknologi Industri Universitas Islam Indonesia

[3] Kusumadewi, Sri, 2003, "Artificial Intelegence Teknik dan Aplikasinya”. Jogjakarta: Graha Ilmu Kosko, Bart, 1997, "Fuzzy Engineering”. New Jersey: Prentice - Hall, Inc.

[4] Pratikno, Budi, 2003, "Aplikasi Fuzzy Servqual untuk Menganalisa Kepuasan Pelanggan terhadap Kualitas Pelayanan Jasa Pendidikan (Studi Kasus Pada Universitas Muhammadiyah Surakarta)”. 